Article

\title{
Database Analysis of Depression and Anxiety in a Community Sample-Response to a Micronutrient Intervention
}

\author{
Samantha M. Kimball ${ }^{1,2, *}$, Naghmeh Mirhosseini ${ }^{1}$ (D) and Julia Rucklidge ${ }^{3}$ \\ 1 Pure North S’Energy Foundation, Calgary, AB T2R 0C5, Canada; Naghmeh.Mirhosseini@purenorth.ca \\ 2 Department of Natural and Mathematical Sciences, St. Mary's University, Calgary, AB T2X 1Z4, Canada \\ 3 Department of Psychology, University of Canterbury, Christchurch 8140, New Zealand; \\ Julia.rucklidge@canterbury.ac.nz \\ * Correspondence: Samantha.Kimball@purenorth.ca; Tel.: +1-403-457-5077
}

Received: 5 December 2017; Accepted: 26 January 2018; Published: 30 January 2018

\begin{abstract}
Background: Depression and anxiety are common mental health concerns worldwide. Broad-spectrum multi-vitamin/mineral approaches have been found to alleviate a number of psychiatric symptoms. We investigated the effects of a nutrient intervention program, which includes optimizing vitamin D levels, on depression and anxiety outcomes from community-based program. Methods: We evaluated self-reported health measures of depression and anxiety collected as part of a community-based program focused on optimizing overall health through nutritional supplementation, education and lifestyle advice. Results: Data were collected from 16,020 participants, with measures including European Quality of Life Five Dimensions (EQ-5D) and Targeted Symptoms List (TSL) providing self-reported depression and anxiety. More than 56\% of participants were identified as having elevated levels of depression and anxiety at baseline as reported on the EQ-5D. After one year in the program, $49.2 \%(n=7878)$ of participants who reported any level of depression or anxiety at baseline reported improvement at follow-up. Of those who reported severe/extreme depression at baseline $(n=829), 97.2 \%$ reported improvement after one year. Regression analyses revealed a significant association of improvement in depression and anxiety with higher vitamin D status (>100 nmol/L) and more strenuous physical activity. Conclusion: Overall, people from the general population who suffer from mood and anxiety problems may benefit from improved nutritional status achieved with nutritional supplements.
\end{abstract}

Keywords: depression; anxiety; vitamin D; nutritional supplements; multivitamin/multimineral; mental health

\section{Introduction}

The World Health Organization estimates that 350 million people worldwide are affected by depression and anxiety. The Global Burden of Disease Study in 2010 identified depressive disorders as a leading cause of burden and responsible for 3.8\% of global Disability Adjusted Life Years (DALY) [1]. As a contributor to DALY, depression is expected to be the second highest concern for all ages by 2020 [2]. In Canada, it is estimated that over 6.7 million people live with a mental health problem (in comparison with 3.5 million with type 2 diabetes mellitus) [3]. Economic costs of mental health problems are estimated to be at least $\$ 50$ billion per year [3]. With current medications purported to only have a modest benefit [4], few new psychiatric drugs on the horizon, and some studies suggesting medication can do more harm than good [5-8], there are calls to revisit the impact that nutrition can have on mental health $[4,9]$.

Biologically, nutrition is interconnected with depression through hormonal, neurotransmitter and signalling pathways in the gut that modulate brain functions such as appetite, sleep, reward 
mechanisms, cognitive function and mood [10]. All biochemical pathways require vitamins and minerals as co-factors for proper enzyme function and insufficient nutrient levels can negatively impact a wide range of metabolic processes. There are a number of different nutrients involved in pathways relevant to mental disorders and brain function [11].

Many nutrients have been investigated individually, including: B vitamins, vitamin D, choline, iron, zinc, magnesium, S-adenosyl methionine, amino acids such as taurine and probiotics. For the most part, studies of single nutrient treatments for mood disorders such as vitamin D report only modest symptom improvement or null results [12]. The evidence for B vitamins is stronger, such that a systematic review reported sufficient evidence to support the use of combination high dose B vitamins in the treatment of stress and anxiety in the general population [13]. Overall, no single nutrient stands out as a treatment for mental health problems. However, a broad-spectrum multivitamin and multimineral approach may alleviate symptoms in a number of psychiatric ailments.

Nutrition and dietary patterns have been linked with depression onset, and the maintenance and severity of symptoms [14-17]. Furthermore, several trials have demonstrated improvements in not only depression, but anxiety and stress response through supplementation with multivitamin/multimineral formulas and B complex vitamins [18-23]. In fact, the International Society for Nutritional Psychiatry Research has issued a consensus statement that "nutrition and nutraceuticals should now be considered as mainstream elements of psychiatric practice, with research, education, policy and health promotion reflecting this new paradigm [24]". A full range of vitamins and minerals are obligatory cofactors involved in the production of neurotransmitters. For example, in the production of serotonin, the major neurotransmitter involved in depressive disorders, there are requirements for vitamin B6, vitamin D, iron, copper and molybdenum.

A multivitamin/mineral (MVM), in which many ingredients were given at levels higher than recommended dietary allowance (RDA) but generally lower than the upper level (UL), has been shown to improve depressive symptoms in bipolar individuals [25-29]. A MVM was also found to significantly reduce stress and anxiety following a series of earthquakes and a flood [22,29-31]. Despite enrolling participants who were not clinically depressed, two clinical trials have found that micronutrient supplementation improved symptoms of depression [32,33]. Collectively, the evidence suggests that a spectrum of nutrients may be effective for reducing and preventing depression, stress and anxiety. We hypothesized that optimal nutrient status, as measured by serum 25-hydroxyvitamin $\mathrm{D}(25(\mathrm{OH}) \mathrm{D})$ levels above $100 \mathrm{nmol} / \mathrm{L}$ [34] and serum vitamin B12 above $450 \mathrm{pmol} / \mathrm{L}$ [35], would have a protective effect against depression and anxiety and that supplementation to achieve "optimal" nutrient status would improve depression and anxiety.

In the present study, we characterize the prevalence and severity of symptoms of depression and anxiety in participants in a community-based prevention program, before and after one year of exposure to nutritional supplements (a combination of vitamin D3, MVM and other nutrients), to determine if there was a benefit of supplementation with a broad spectrum of nutrients in a comparison sample. We further investigated the impact of supplementation in a subgroup of participants who self-reported extreme or severe depression and anxiety at entry to the program.

\section{Materials and Methods}

\subsection{Intervention}

The Pure North S'Energy Foundation (Pure North) is a not-for-profit wellness program focused on the prevention of chronic diseases including mental illness, type 2 diabetes mellitus, cardiovascular disease and cancer. The Pure North program offers lifestyle advice, education and nutritional supplements to its participants. Dietary advice typically includes aspects of the DASH diet developed to lower blood pressure without medication when appropriate for physical health outcomes, proper food portion education, encouraging plenty of fruit and vegetables (5-10 servings/day) and foods rich in omega-3 fatty acids, restriction of added sugar to less than $25 \mathrm{~g} /$ day and sodium to less than 
$2300 \mathrm{mg} /$ day. Other lifestyle advice consists of proper sleep hygiene, smoking cessation, at least 150 min of physical activity each week and moderate alcohol consumption.

Supplement recommendations are based on analysis of each participant's biometric measurements (including BMI), blood results and clinical intake data. Health care professionals review and explain blood work results with the participant and, based on their clinical knowledge and nutrient expertise, make recommendations accordingly. Each participant is treated as an individual and a treatment plan developed to meet that individual's nutrient requirements. All participants are encouraged to achieve a $25(\mathrm{OH}) \mathrm{D}$ level of at least $100 \mathrm{nmol} / \mathrm{L}$ and vitamin $\mathrm{D}$ dosages were adjusted accordingly for the individual.

The core supplements provided to everyone are in daily packets, Vitality Packs, and contain: the multivitamin and multimineral formula (Vital 2 Platinum; Table S1), Omega-3 fatty acids (400 mg EPA and $200 \mathrm{mg}$ DHA), Vitamin C (1000 mg), Vitamin B12 (5000 $\mu \mathrm{g}$ methylcobalamin), Probiotics (Biffidobacterium and Lactobacillus strains, 10 billion CFU) and Vitamin D3 drops. Vitamin D3 supplementation is individualized to target an optimal serum 25-hydroxyvitmainD $(25(\mathrm{OH}) \mathrm{D})$ concentration, above $100 \mathrm{nmol} / \mathrm{L}$ [36]. Doses of vitamin D3 are often in excess of the UL (4000 IU/d) and given under medical supervision [37]. Further supplements in addition to the Vitality Packs may be recommended based on individual requirements.

\subsection{Assessments}

Participants in the Pure North program are assessed at each visit to the clinic. Visits typically occur every 6-12 months to monitor lifestyle modification or disease condition change, and to adjust supplement doses if required. Any participant with obvious clinical depression or anxiety who requires closer monitoring or psychiatric medications is referred to their family physician. Assessments include biometrics (including blood pressure, height, weight, BMI, etc.), clinical intake (including medical history (such as pernicious anemia and H. pylori infections that might affect vitamin B12 absorption), current medications (including acid blockers and proton pump inhibitors that might affect vitamin B12 absorption), complaints and health goals), blood work (a number of biomarkers are measured including serum $25(\mathrm{OH}) \mathrm{D}$, vitamin B12, arachidonic acid (AA) and eicosapentaenoic acid (EPA)), and completion of a questionnaire (including demographic data and self-reported health assessments). All blood sample preparation and biochemical measurements were performed by Doctor's Data Laboratory (St. Charles, IL, USA), a fully accredited laboratory. Serum $25(\mathrm{OH}) \mathrm{D}$ was measured using Liquid Chromatography and tandem Mass Spectrometry (LC/MS-MS) with the inter-assay CV of $2.4 \%$. Serum vitamin B12 was measured on an automated analyser with a chemiluminescent immunoassay (Beckman Coulter) with a CV of 7.7\%. AA and EPA were measured using gas chromatography.

For the present study, we utilized serum $25(\mathrm{OH}) \mathrm{D}$ and vitamin $\mathrm{B} 12$ concentrations, available measures of nutrient status. Low levels of vitamin D have previously been linked to mental health disorders, including mood disorders such as depression [38-40]. Vitamin D is of particular interest due to its various roles in the brain and in neurotransmitter synthesis [41] and the heightened prevalence of vitamin D deficiency (serum $25(\mathrm{OH}) \mathrm{D}<50 \mathrm{nmol} / \mathrm{L}$ ) and mood disorders in Canada (more than $32 \%$ and nearly $13 \%$, respectively) [42,43]. B vitamins are important for adrenal support, energy production and neurotransmitter synthesis [44] and vitamin B12 deficiency $(<148 \mathrm{pmol} / \mathrm{L})$ is common worldwide [45]. Serum vitamin B12 is a measurable indicator of B12 status. Unfortunately, we are not easily and reliably able to measure the status of all nutrients in the body.

\subsection{Self-Reported Depression and Anxiety}

The European Quality of Life Five Dimensions (EQ-5D) assessment is a standardised instrument used to measure health status in a wide range of health conditions and treatments. The EQ-5D is a widely used questionnaire for calculating quality-adjusted life years (QALYs) for assessing cost-effectiveness in healthcare. Participants complete the EQ-5D at each visit to the clinic. The EQ-5D reflects the impact of common mental health conditions, such as mild to moderate depression and 
anxiety, on daily function [36] and has been found to be sensitive enough to pick up improvements associated with treatment in patients with depression [46]. We utilized the EQ-5D to investigate self-reported depression and anxiety in a community sample.

In addition to the EQ-5D participants completed the Targeted Symptoms List (TSL)—a wellbeing assessment tool developed in-house. The TSL assesses 16 mental and physical health outcomes on a scale of 1-10 $(1=$ never through to $10=$ always $)$ with a focus on common health complaints including: anger, anxiety, confusion, coordination problems, depression, fatigue, headache, joint pain, loss of sense (smell/taste), memory loss, moodiness, muscle weakness, numbness in arms/legs, shakiness of hands, stomach problems (digestive), and unintentionally dropping things. In addition, the TSL mental health score (MHS) is a composite score of depression, anxiety, and moodiness. For the purposes of the present study, we have focused on 3 TSL scores: depression, anxiety and the calculated MHS.

Depression and anxiety were measured via self-report in the population at baseline, the time of their first interaction with the Pure North program with a closer look at participants who reported severe or extreme depression/anxiety on the EQ-5D. We further utilized blood markers of nutritional status, 25(OH)D and vitamin B12, to investigate whether the effects of the nutrition-based intervention on levels of reported depression, anxiety and MHS were associated with changes in these nutrients over time.

This study was an analysis conducted utilizing a database of participant information collected as part of a community program (secondary use of data). The protocol of current database analysis was approved by the Research Ethics Board at St. Mary's University in Calgary, Alberta (File\# 073FA2017). Informed consent was obtained from all individual participants included in the study to use their information to evaluate the program.

\subsection{Statistical Analyses}

Statistical analyses were completed using SPSS v23 (SPSS Inc., Chicago, IL, USA). Descriptive statistics are presented as mean \pm standard deviation. Intent-to-treat analyses were performed; as such mean follow-up values were used for participants who had baseline measures but not follow-up measures (mean imputation method). Since the data were not normally distributed, non-parametric tests were applied. Wilcoxon Signed Rank Test (WSRT) was performed to evaluate changes in different parameters over one-year. Mann-Whitney U-test and Kruskal-Wallis tests were utilized to compare categorical groups of vitamin D and vitamin B12 status. Chi Square testing was performed to determine the association between levels of anxiety and depression and $25(\mathrm{OH}) \mathrm{D}(>100 \mathrm{nmol} / \mathrm{L})$ and $\mathrm{B} 12$ status ( $>450 \mathrm{pmol} / \mathrm{L}$ ). Binary Logistic Regression was performed to investigate the relationship between $25(\mathrm{OH}) \mathrm{D}$ and vitamin B12 with changes in mental health status over time. Body mass index (BMI), age, gender, tobacco use, alcohol use, physical activity, fruit and vegetable consumption, fish and tuna consumption, AA:EPA and inflammation (CRP $\geq 10 \mathrm{mg} / \mathrm{L}$ ) were considered as cofactors in these analyses. Significance was defined as $p<0.05$. For determining effect size (ES), Cohen's test was conducted using STATA version 14. Cohen's $d$ was used to estimate effect sizes, with 0.2 indicating a small effect, 0.5 a medium effect and 0.8 a large effect.

\section{Results}

\subsection{Baseline Demographics}

Data were collected for 16,020 participants (60\% female) who entered the program and completed an EQ-5D. The mean age was $54.2 \pm 16.0$ (range 18-95) years. Of these, 1971 (16\%) self-reported mental health problems or previous diagnoses of depression, anxiety, stress, Attention-Deficit/Hyperactivity Disorder (ADHD), Post-Traumatic Stress Disorder (PTSD), Seasonal Affective Disorder (SAD), or other mental health disorders. There were $2123(20 \%)$ who reported taking medications used to treat depression and anxiety, of which $45.0 \%$ reported both depression or anxiety and taking medication. At program entry, serum 25(OH)D level was not significantly different between participants taking 
medication $(77.8 \pm 27 \mathrm{nmol} / \mathrm{L})$ and those not $(77.9 \pm 27 \mathrm{nmol} / \mathrm{L})$. There were 3875 participants who reported hypertension, 1656 with diabetes, and 1642 cases of cancer (past or present). Vitality packs were provided for $96 \%$ of participants and equivalent supplements provided to the remaining $4 \%$ who did not take the vitality pack for various reasons (e.g., one of the supplements was deemed unnecessary or did not agree with the participant). In addition, $44 \%$ of participants were recommended extra nutrients based on individual need.

The body mass index (BMI) distribution was 35.0\% normal (18.5-24.9), 35.7\% overweight (25-29.9) and $27.7 \%$ obese $(>30)$, similar to the measured BMIs for the Canadian population reported by Statistics Canada at $36.1 \%, 36.8 \%$ and $25.1 \%$, respectively [47]. At program entry, $84.0 \%$ of participants were considered to have suboptimal vitamin D levels $(25(\mathrm{OH}) \mathrm{D}<100 \mathrm{nmol} / \mathrm{L})$ with $14.7 \%$ being deficient $(25(\mathrm{OH}) \mathrm{D}<50 \mathrm{nmol} / \mathrm{L})$. Suboptimal vitamin B12 levels, $<450 \mathrm{pmol} / \mathrm{L}$, were found in $75.5 \%$ of participants at baseline. Medical conditions that can influence vitamin B12 absorption were investigated. In the four cases of pernicious anemia, serum vitamin B12 levels increased from 214 to $1159 \mathrm{pmol} / \mathrm{L}$, similar to response found in the rest of the population. There were three cases with H. pylori infection in whom serum vitamin B12 levels increased from 308 to 503 pmol/L. Twelve percent of participants were taking acid blockers, such as proton pump inhibitors, with no significant difference in serum vitamin B12 levels between participants taking (427 \pm 1543 increased to $1049 \pm 2662$ pmol/L) and those not taking (421 \pm 1047 increased to $995 \pm 1264$ pmol/L) acid blockers.

More than half of participants $(56.2 \%)$ reported some level of depression or anxiety at the entry to the program (Table 1). Eighty-one per cent of participants who reported a history of depression or anxiety and $87 \%$ who reported taking medications for depression and anxiety, reported low levels of depression and anxiety at baseline (none to moderate). Five percent $(5.2 \%)$ of the population reported severe or extreme depression at program entry, with more than half of those having reported a history of or taking medications for depression/anxiety (Table 1). After one year in the program, there was no significant difference in serum $25(\mathrm{OH}) \mathrm{D}$ levels between participants taking anxiety or depression-related medication $(111 \pm 31 \mathrm{nmol} / \mathrm{L})$ and those not taking medications $(112 \pm 32 \mathrm{nmol} / \mathrm{L})$. There was no significant difference in the proportion of participants taking medications for anxiety or depression $(1.0 \%)$ in comparison with those not taking medications $(1.3 \%)$.

Table 1. Baseline demographics and self-reported levels of anxiety and depression on European Quality of Life Five Dimensions (EQ-5D).

\begin{tabular}{ccccc}
\hline $\begin{array}{c}\text { Level of Anxiety or Depression } \\
\text { Reported on EQ-5D }\end{array}$ & Total (\%) & Female (\%) & $\begin{array}{c}\text { \% with Reported History of } \\
\text { Depression/Anxiety }\end{array}$ & $\begin{array}{c}\text { \% with Reported Medication } \\
\text { Use for Depression/Anxiety }\end{array}$ \\
\hline None & $7014(43.8)$ & $3951(56.3)$ & $231(4.4)$ & $418(9.3)$ \\
Slight & $5417(33.8)$ & $3451(63.7)$ & $598(14.3)$ & $702(20.3)$ \\
Moderate & $2763(17.2)$ & $1675(60.6)$ & $772(34.0)$ & $718(38.8)$ \\
Severe & $577(3.6)$ & $323(56.0)$ & $243(49.5)$ & $184(46.5)$ \\
Extreme & $249(1.6)$ & $156(62.7)$ & $127(62.3)$ & $101(61.2)$ \\
Total & $16,020(100)$ & $9556(59.7)$ & $1971(16)$ & $2123(20.5)$ \\
\hline
\end{tabular}

The severity of depression/anxiety was also significantly correlated with several lifestyle characteristics (Table S2). Participants who reported severe or extreme depression/anxiety at program entry often consumed no fruit $(p<0.001)$, vegetables $(p<0.001)$, and fish $(p=0.03)$ or consumed fewer servings relative to those who were not depressed/anxious. Participants who used tobacco $(p<0.001)$, drank heavily $(p<0.001)$ and were less physically active $(p<0.001)$, were also likely to report severe or extreme depression/anxiety at program entry. Serum $25(\mathrm{OH}) \mathrm{D}$ levels were significantly lower in depressed/anxious participants who were less physically active $(66.5 \pm 28 \mathrm{nmol} / \mathrm{L})$ compared to those who were more physically active $(76 \pm 24 \mathrm{nmol} / \mathrm{L})$.

Because of the often cited ceiling effect found with the EQ-5D [48-50], we utilized a second measure of depression and anxiety from an in-house questionnaire, the TSL, which had been previously validated against both the EQ-5D and the SF-12 Health Survey. Reported depression/anxiety on the EQ-5D is compared with TSL scores in Table 2. The depression/anxiety aspect of the EQ-5D followed similar distribution patterns as TSL scores. Reported depression/anxiety on the EQ-5D had a 
significant correlation with the TSL anxiety $(r=0.66, p<0.001)$, depression $(r=0.67, p<0.001)$ and MHS $(r=0.71, p<0.001)$. In addition, the TSL mental health score significantly correlated with the SF-12's Mental Component Summary (MCS-12) score in a subset of participants who completed both ( $n=2084, r=0.68, p<0.001$; data not shown). These results support the use of the MHS to assess mental wellbeing and to investigate nutrient effects on depression and anxiety in this population.

Table 2. Baseline Comparison of European Quality of Life Five Dimensions (EQ-5D-Rated) Level of Depression/Anxiety to Targeted Symptoms List (TSL) Scale Scores for Depression and Anxiety.

\begin{tabular}{|c|c|c|c|c|c|c|}
\hline $\begin{array}{c}\text { EQ-5D } \\
\text { Depression/Anxiety }\end{array}$ & $\begin{array}{c}\text { Mean TSL } \\
\text { Depression Score }\end{array}$ & ${ }^{*} p$-Value & $\begin{array}{c}\text { Mean TSL } \\
\text { Anxiety Score }\end{array}$ & ${ }^{*} p$-Value & $\begin{array}{l}\text { Mean TSL Mental } \\
\text { Health Score }\end{array}$ & ${ }^{*} p$-Value \\
\hline None & $1.95 \pm 1.5$ & & $2.21 \pm 1.6$ & & $2.11 \pm 1.3$ & \\
\hline Slight & $4.00 \pm 2.0$ & & $4.33 \pm 2.0$ & & $3.98 \pm 1.7$ & \\
\hline Moderate & $5.84 \pm 2.3$ & $<0.001$ & $6.25 \pm 2.2$ & $<0.001$ & $5.68 \pm 1.8$ & $<0.001$ \\
\hline Severe & $7.50 \pm 2.3$ & & $7.69 \pm 2.2$ & & $7.11 \pm 1.8$ & \\
\hline Extreme & $8.00 \pm 2.6$ & & $8.31 \pm 2.4$ & & $7.57 \pm 2.2$ & \\
\hline
\end{tabular}

\subsection{Comparison between Baseline and One-Year Follow-Up}

All participants at baseline were included in this intent-to-treat analysis $(n=16,020)$. There were 4159 participants who returned for their follow-up in the clinic within 6-18 months after the initial visit, average 12 months. A comparison of baseline measures between participants who persisted in the program (returned for follow-up in the specified time frame) and those that did not, found that Persisters were older, more were female, they had higher baseline 25(OH)D and vitamin B12 levels, lower AA:EPA and reported less depression (mean 3.04 vs. 3.73 on TSL) and anxiety (mean 3.36 vs. 4.04 on TSL) (Table 3).

Table 3. Baseline comparison of Participants who stay in the program for one year (Persisters) to those that had a baseline visit only (Drop-outs).

\begin{tabular}{|c|c|c|c|c|}
\hline \multicolumn{2}{|r|}{ Variable } & Persisters $(n=4159)$ & Drop-outs $(n=11,861)$ & $p$ Value \\
\hline \multicolumn{2}{|c|}{ Age (years) } & $62.9 \pm 11.9$ & $51.1 \pm 16.7$ & $<0.001 *$ \\
\hline \multicolumn{2}{|c|}{$\%$ Female } & 63.4 & 58.3 & $<0.001^{\#}$ \\
\hline \multicolumn{2}{|l|}{ BMI } & $27.6 \pm 5.5$ & $27.5 \pm 5.8$ & 0.6 \\
\hline \multicolumn{2}{|c|}{ 25(OH)D (nmol/L) } & $85 \pm 31$ & $73 \pm 27$ & $<0.001 *$ \\
\hline \multicolumn{2}{|c|}{ Vitamin B12 (pmol/L) } & $454 \pm 325$ & $358 \pm 286$ & $<0.001 *$ \\
\hline \multicolumn{2}{|c|}{ AA:EPA } & $13.6 \pm 7.1$ & $18.3 \pm 7.7$ & $<0.001 *$ \\
\hline \multicolumn{5}{|c|}{ EQ-5D Depression and Anxiety, $n$ (\%): } \\
\hline- & None & $2130(51.2)$ & $4884(41.2)$ & \\
\hline- & Slight & $1329(32)$ & $4088(34.5)$ & \\
\hline- & Moderate & $585(14.1)$ & 2178 (18.4) & $<0.001^{\#}$ \\
\hline- & Severe & $84(2)$ & $493(4.2)$ & \\
\hline- & Extreme & $31(0.7)$ & $218(1.8)$ & \\
\hline \multicolumn{2}{|c|}{ TSL mental health score } & $3.04 \pm 2.0$ & $3.75 \pm 2.2$ & $<0.001$ * \\
\hline \multicolumn{2}{|c|}{ TSL anxiety } & $3.36 \pm 2.3$ & $4.04 \pm 2.6$ & $<0.001$ * \\
\hline \multicolumn{2}{|c|}{ TSL depression } & $3.04 \pm 2.3$ & $3.73 \pm 2.6$ & $<0.001$ * \\
\hline
\end{tabular}

After an average of one year, we examined levels of depression/anxiety reported on the EQ-5D at follow-up. Overall, 46.8\% of participants did not report any change in their level of depression/anxiety, whereas $4.1 \%$ reported higher levels and $49.2 \%$ reported improvement (Table 4 ). Of those who reported severe/extreme depression at baseline [ $n=577$ (severe), $n=249$ (extreme)], 97.2\% reported improvement, $2.4 \%$ reported no change and $0.4 \%$ were worse after one year in the program (Chi-square, $p<0.05)$. For those who reported none/slight/moderate levels of depression or 
anxiety, 58.4\% improved, 3.6\% worsened and 38\% did not report any change. Per protocol analyses revealed similar results to ITT (data available upon request).

Table 4. Change in Reported Level of Depression and Anxiety at One Year.

\begin{tabular}{ccccc}
\hline \multirow{2}{*}{ Baseline Level of Depression/Anxiety } & \multicolumn{4}{c}{ Change at One Year Number (\%) } \\
\cline { 2 - 5 } & Worse & Improve & No Change & Total \\
\hline None & $430(6.1)$ & 0 & $6584(93.9)$ & 7014 \\
Slight & $177(3.3)$ & $4569(84.3)$ & $671(12.4)$ & 5417 \\
Moderate & $40(1.4)$ & $2511(90.9)$ & $212(7.7)$ & 2763 \\
Severe & $4(0.7)$ & $552(95.7)$ & $21(3.6)$ & 577 \\
Extreme & 0 & $246(98.8)$ & $3(1.2)$ & 249 \\
Total & $651(4.1)$ & $7878(49.2)$ & $7491(46.8)$ & 16,020 \\
\hline Chi-Square & \multicolumn{4}{c}{$p<0.001$} \\
\hline
\end{tabular}

We validated the use of TSL scores as a numeric scale by comparing baseline TSL scores between those who reported severe/extreme depression on the EQ-5D with those who reported none, slight or moderate levels. As expected, those who reported severe/extreme depression/anxiety on the EQ-5D had significantly higher mean TSL scores than the rest of the population for both depression (7.65 \pm 2.4 vs. $3.4 \pm 2.4$, respectively) and anxiety ( $7.9 \pm 2.3$ vs. $3.7 \pm 2.4$, respectively). Effect sizes were used to compare the magnitude of change between baseline and follow-up. Effect sizes were much larger for those who started the nutrients in a severe/extreme depressed or anxious state (Table 5).

Table 5. Effect Sizes (ES) * for Targeted Symptoms List (TSL) Levels of Depression, Anxiety and Mental Health Score.

\begin{tabular}{ccc}
\hline TSL Score & $\begin{array}{c}\text { EQ-5D “Severe/Extreme” for } \\
\text { Depression/Anxiety }\end{array}$ & $\begin{array}{c}\text { EQ-5D “None/Slight/Moderate” } \\
\text { for Depression/Anxiety }\end{array}$ \\
\hline ES for Depression & $1.85(1.71-1.99)$ & $0.21(0.18-0.23)$ \\
ES for Anxiety & $1.94(1.80-2.08)$ & $0.22(0.19-0.24)$ \\
ES for MHS & $2.07(1.93-2.22)$ & $0.27(0.24-0.30)$ \\
N & 563 & 11,033 \\
\hline
\end{tabular}

* Cohen's d (with 95\% confidence intervals) measure of effect sizes: 0.2 is small, 0.5 is medium, and 0.8 is large MHS $=$ Mental Health Score .

We examined the effect of the nutrient intervention program on changes in measured nutrients, serum 25(OH)D, vitamin B12 and AA:EPA in relation to baseline depression/anxiety level. Similar significant improvements in $25(\mathrm{OH}) \mathrm{D}$, vitamin $\mathrm{B} 12$ and AA:EPA were found in both groups (severe/extreme vs. none/slight/moderate), without any reported side effects (Table 6). Per protocol analyses revealed similar results to ITT (data available upon request).

After one year in the program, more than $62 \%$ of participants had serum $25(\mathrm{OH}) \mathrm{D}$ levels above $100 \mathrm{nmol} / \mathrm{L}$ compared to $25 \%$ at baseline. Kimball et al. (2017) [37], assessing safety in the Pure North population, previously showed that serum 25(OH)D levels up to $300 \mathrm{nmol} / \mathrm{L}$ were found to be safe, without any evidence of toxicity. In the current study, following vitamin D supplementation and a significant increase in serum $25(\mathrm{OH}) \mathrm{D}$ levels over time, no participant obtained a level above $300 \mathrm{nmol} / \mathrm{L}$ and there were no cases of vitamin D toxicity.

To investigate whether the improvements in depression and anxiety were related to the nutrient supplementation program, we utilized serum 25(OH)D and vitamin B12 levels. We compared 25(OH)D and vitamin B12 levels between those participants who reported being severe/extreme depressed or anxious versus being none/slight/moderate depressed or anxious at baseline (Table 7). We compared the magnitude of the changes between baseline and one year in participants considered deficient with those who had reached optimal levels for vitamin D and B12 at follow-up, for both categories. Among those who were severe/extreme anxious or depressed, moderate effect sizes, ranging from 0.5 to 0.6 , 
were found in participants who remained below optimal vitamin B12 levels $(<450 \mathrm{pmol} / \mathrm{L})$ and serum 25(OH)D levels (<100 nmol/L). In contrast, those participants who achieved optimal vitamin B12 and optimal 25(OH)D at follow up, experienced significant improvements in depression, anxiety and MHS on TSL with effect sizes in the range of 1.95 to 2.33. In participants with optimal vitamin B12 and serum $25(\mathrm{OH}) \mathrm{D}$ at baseline, the effect sizes for depression/anxiety outcomes were similar to effect sizes when either 25(OH)D levels or vitamin B12 levels were in the optimal range alone. Among those who were none/slight/moderate anxious or depressed at baseline, there was no effect of the program when participants had low vitamin B12 $(<450 \mathrm{pmol} / \mathrm{L})$ and $25(\mathrm{OH}) \mathrm{D}$ levels $(<100 \mathrm{nmol} / \mathrm{L})$ with small but significant ES in those with high vitamin B12 and $25(\mathrm{OH}) \mathrm{D}$ that ranged from 0.22 to 0.29 . Effect sizes were similar but much larger in those who were in the severe/extreme group, with effect sizes that ranged from 1.95 to 2.33 in the high vitamin B12 and 25(OH)D groups (Table 7). Per protocol analyses revealed similar results to ITT (data available upon request).

Table 6. Comparison of biomarkers of nutrition with levels of depression and anxiety.

\begin{tabular}{|c|c|c|c|c|}
\hline \multirow[t]{2}{*}{ Parameter } & \multicolumn{2}{|c|}{$\begin{array}{l}\text { Depressed/Anxious (Severe/Extreme) } \\
\qquad(n=826)\end{array}$} & \multicolumn{2}{|c|}{$\begin{array}{c}\text { Less Depressed/Anxious } \\
\text { (None/Slight/Moderate) }(n=15,194)\end{array}$} \\
\hline & Baseline & One Year & Baseline & One Year \\
\hline Age (years) & $47.2 \pm 16$ & - & $54.6 \pm 16$ & - \\
\hline BMI & $27.6 \pm 6.6$ & $27.7 \pm 2.9$ & $27.5 \pm 5.6$ & $27.6 \pm 3.0$ \\
\hline Serum 25(OH)D (nmol/L) & $71 \pm 28$ & $111 \pm 16^{\mathrm{a}}$ & $76 \pm 28$ & $112 \pm 19^{a}$ \\
\hline Serum Vitamin B12 (pmol/L) & $395 \pm 360$ & $1089 \pm 420^{a}$ & $383 \pm 297$ & $1090 \pm 832^{a}$ \\
\hline AA:EPA & $18.9 \pm 7.8$ & $8.9 \pm 5.0^{\mathrm{b}, \mathrm{c}}$ & $15.4 \pm 7.7$ & $8.9 \pm 4.6^{b}$ \\
\hline TSL Depression & $7.6 \pm 2.4$ & $3.7 \pm 1.8^{\mathrm{b}, \mathrm{c}}$ & $3.4 \pm 2.4$ & $2.9 \pm 1.2^{b}$ \\
\hline TSL Anxiety & $7.9 \pm 2.3$ & $3.9 \pm 1.8^{\mathrm{b}, \mathrm{c}}$ & $3.7 \pm 2.4$ & $3.2 \pm 1.2^{b}$ \\
\hline TSL Mental Health Score & $7.2 \pm 1.9$ & $3.6 \pm 1.6^{\mathrm{b}, \mathrm{c}}$ & $3.4 \pm 2.0$ & $2.9 \pm 1.0^{b}$ \\
\hline
\end{tabular}

${ }^{a}$ Indicates significant difference from baseline within group, paired-t; ${ }^{b}$ Indicates significant difference from baseline within group, WSRT; ' Indicates a significant difference between groups (Depressed/Anxious vs. Everyone Else), Mann-Whitney U.

The effect of the nutrients on mental health outcomes were assessed with a nested case control analysis. We selected 107 participants who were severely/extremely depressed/anxious (based on EQ-5D) but did not take any psychiatric medication (cases), and compared them with 214 severely/extremely depressed/anxious participants, matched based on age, sex and BMI, who took related psychiatric medication (controls). Following one year in program, nutrient levels significantly increased in both the case and control groups. Serum $25(\mathrm{OH}) \mathrm{D}$ levels were higher in participants who were not taking psychiatric medications in comparison with those taking medications at both baseline and follow-up. There was no significant difference between depressed/anxious participants taking vitamins and those taking both vitamins and medications (Table 8).

We additionally compared EQ-5D score improvements between depressed/anxious participants taking no medication (cases) and those taking medication (controls). Again, we did not find any significant difference between case and control groups (Table S3). In both groups, more than $90 \%$ showed improvement in their mental status and the rest remained unchanged, regardless of their related psychiatric medication status. No participants reported a worsened mental status.

We further investigated the effects of nutrient status on mental health outcomes through logistic regression analyses. Participants taking anxiety- and/or depression-related medications were excluded from the regression analysis $(n=700)$. Improvements in serum $25(\mathrm{OH}) \mathrm{D}$ concentration, such that participants went from having suboptimal levels to optimal levels ( $\geq 100 \mathrm{nmol} / \mathrm{L}$ for $25(\mathrm{OH}) \mathrm{D})$, were found to be associated with improvements in anxiety, depression and MHS (Table 9). In addition, physical activity significantly influenced anxiety and depression scores with moderate and strenuous physical activity related to larger improvements to MHS. Age also influenced anxiety, depression and MHS with younger participants showing larger improvements. Current tobacco use and inflammation negatively affected mental health status. 
Table 7. Magnitude of Effect of Nutritional Status on Targeted Symptoms List (TSL) Depression and Anxiety at one-year follow-up in Severely/Extremely Anxious/Depressed.

\begin{tabular}{|c|c|c|c|c|c|c|}
\hline \multicolumn{7}{|c|}{ Effect Size Between Baseline and One-Year (95\% CI) } \\
\hline TSL Parameters & $\begin{array}{c}\text { Low Vitamin B12 } \\
(<450(\mathrm{pmol} / \mathrm{L}))\end{array}$ & $\begin{array}{l}\text { High Vitamin B12 } \\
(\geq 450 \mathrm{pmol} / \mathrm{L})\end{array}$ & $\begin{array}{c}\text { Low Serum 25(OH)D } \\
<100 \mathrm{nmol} / \mathrm{L}\end{array}$ & $\begin{array}{l}\text { High Serum 25(OH)D } \\
\geq 100 \mathrm{nmol} / \mathrm{L}\end{array}$ & $\begin{array}{c}\text { Combined Low B12 } \\
\text { and 25(OH)D }\end{array}$ & $\begin{array}{l}\text { Combined High B12 } \\
\text { and 25(OH)D }\end{array}$ \\
\hline \multicolumn{7}{|c|}{ Severely/Extremely Anxious/Depressed } \\
\hline Depression & $0.59[-0.01-1.20]$ & 1.95 [1.80-2.09] & $0.80[0.37-1.24]$ & $2.01[1.86-2.16]$ & $0.61[-0.13-1.34]$ & $2.05[1.90-2.20]$ \\
\hline Anxiety & $0.60[-0.01-1.20]$ & $2.04[1.89-2.19]$ & $0.65[0.22-1.07]$ & $2.13[1.98-2.28]$ & $0.66[-0.08-1.39]$ & $2.18[2.03-2.33]$ \\
\hline Mental score & $0.57[-0.05-1.18]$ & $2.20[2.05-2.35]$ & $0.78[0.35-1.22]$ & $2.28[2.12-2.44]$ & $0.54[-0.19-1.27]$ & $2.33[2.17-2.49]$ \\
\hline N & 24 & 539 & 47 & 516 & 15 & 510 \\
\hline \multicolumn{7}{|c|}{ None/Slightly/Moderately Anxious/Depressed } \\
\hline Depression & $0.06[-0.04-0.16]$ & $0.22[0.19-0.25]$ & $0.07[-0.01-0.16]$ & $0.23[0.20-0.25]$ & $0.04[-0.09-0.17]$ & $0.23[0.20-0.26]$ \\
\hline Anxiety & $0.07[-0.03-0.18]$ & $0.23[0.20-0.25]$ & $0.11[0.03-0.19]$ & $0.23[0.20-0.26]$ & $0.05[-0.08-0.18]$ & $0.23[0.21-0.26]$ \\
\hline Mental score & $0.10[-0.01-0.20]$ & $0.28[0.26-0.31]$ & $0.12[0.04-0.21]$ & $0.29[0.26-0.32]$ & $0.07[-0.06-0.20]$ & $0.29[0.26-0.32]$ \\
\hline$N$ & 730 & 10,303 & 1067 & 9966 & 452 & 9688 \\
\hline
\end{tabular}

Cohen's d (with confidence intervals) was used as a measure of effect sizes: 0.2 is small, 0.5 is medium, and 0.8 is large.

Table 8. Comparison of biomarkers of nutrition and mental health scores between case and control groups.

\begin{tabular}{|c|c|c|c|c|c|c|c|}
\hline \multirow[t]{2}{*}{ Parameter } & \multicolumn{2}{|c|}{$\begin{array}{c}\text { Depressed/Anxious (Severe/Extreme) } \\
\text { on No Medications (Cases, } n=107 \text { ) }\end{array}$} & \multicolumn{2}{|c|}{$\begin{array}{c}\text { Depressed/Anxious on Medications } \\
\quad \text { (Controls, } n=214)\end{array}$} & \multicolumn{2}{|c|}{ Changes from Baseline } & \multirow[t]{2}{*}{$p$ Value of Changes } \\
\hline & Baseline & One Year & Baseline & One Year & Cases & Controls & \\
\hline Age (years) & $47.2 \pm 15$ & - & $47.1 \pm 15$ & - & - & - & \\
\hline BMI & $27.8 \pm 6.5$ & $27.3 \pm 3.5$ & $27.9 \pm 6.0$ & $27.8 \pm 2.7$ & $-0.54 \pm 5.4$ & $-0.10 \pm 5.5$ & 0.20 \\
\hline Serum 25(OH)D (nmol/L) & $95 \pm 49$ & $130 \pm 51^{\mathrm{a}}$ & $72 \pm 20$ & $106 \pm 37^{a}$ & $34 \pm 45$ & $34 \pm 45$ & 0.81 \\
\hline Serum Vitamin B12 (pmol/L) & $441 \pm 373$ & $1061 \pm 263^{a}$ & $379 \pm 399$ & $1080 \pm 393^{a}$ & $619 \pm 433$ & $701 \pm 548$ & 0.06 \\
\hline AA:EPA & $18.4 \pm 6.2$ & $8.9 \pm 5.4^{b}$ & $18.7 \pm 8.5$ & $10.5 \pm 2.7^{b}$ & $-9.5 \pm 6.2$ & $-8.2 \pm 6.8$ & 0.76 \\
\hline TSL Depression & $7.6 \pm 2.5$ & $3.6 \pm 1.7 \mathrm{~b}, \mathrm{c}$ & $8.2 \pm 1.9$ & $3.9 \pm 2.1^{b}$ & $-4.0 \pm 2.7$ & $-4.4 \pm 2.6$ & 0.36 \\
\hline TSL Anxiety & $8.2 \pm 2.0$ & $4.0 \pm 1.8^{\mathrm{b}, \mathrm{c}}$ & $8.0 \pm 2.2$ & $4.1 \pm 1.9^{b}$ & $-4.1 \pm 2.6$ & $-3.9 \pm 2.7$ & 0.66 \\
\hline TSL Mental Health & $7.4 \pm 1.9$ & $3.6 \pm 1.5^{b, c}$ & $7.5 \pm 1.7$ & $3.8 \pm 1.8^{\mathrm{b}}$ & $-3.8 \pm 2.2$ & $-3.7 \pm 2.3$ & 0.96 \\
\hline
\end{tabular}

a Indicates significant difference from baseline within group, paired-t; ${ }^{\mathrm{b}}$ Indicates significant difference from baseline within group, WSRT; ${ }^{\mathrm{c}}$ Indicates a significant difference between groups (Depressed/Anxious and no meds vs. Depressed/Anxious on meds), Mann-Whitney U. 
Table 9. Binary Logistic Regression of influencing factors on Targeted Symptoms List (TSL) mental parameters over one year.

\begin{tabular}{|c|c|c|c|c|}
\hline TSL Parameter Improvement & Factor & $\operatorname{Exp}(B)$ & $p$ Value & $95 \% \mathrm{CI}$ \\
\hline \multirow{20}{*}{ Anxiety $\left(R^{2}=0.05, p<0.001\right)$} & Age & 0.99 & 0.90 & $0.977-1.021$ \\
\hline & Gender (Male) & 0.91 & 0.75 & $0.526-1.597$ \\
\hline & Serum vitamin $\mathrm{B} 12(\mathrm{BL} \geq 450 \mathrm{pmol} / \mathrm{L}$ and $\mathrm{FL} \geq 450 \mathrm{pmol} / \mathrm{L})$ & Reference & & \\
\hline & Serum vitamin $\mathrm{B} 12(\mathrm{BL}<450$ and $\mathrm{FL}>450 \mathrm{pmol} / \mathrm{L})$ & 0.83 & 0.54 & $0.476-1.475$ \\
\hline & Serum $25(\mathrm{OH}) \mathrm{D}(\mathrm{BL} \geq 100$ and $\mathrm{FL} \geq 100 \mathrm{nmol} / \mathrm{L})$ & Reference & 0.25 & \\
\hline & Serum $25(\mathrm{OH}) \mathrm{D}(\mathrm{BL}<75$ and $\overline{\mathrm{FL}}>100)$ & 1.71 & 0.10 & $0.950-3.455$ \\
\hline & Serum $25(\mathrm{OH}) \mathrm{D}(\mathrm{BL} 75-100$ and $\mathrm{FL} \geq 100)$ & 1.03 & 0.92 & $0.564-1.872$ \\
\hline & BMI, $\mathrm{kg} / \mathrm{m}^{2}$ & 0.98 & 0.70 & $0.522-1.546$ \\
\hline & Tobacco use (Never) & Reference & 0.53 & \\
\hline & Tobacco use (Quit smoking) & 0.89 & 0.70 & $0.522-1.546$ \\
\hline & Tobacco use (current smoker) & 0.51 & 0.26 & $0.156-1.668$ \\
\hline & Alcohol use (Never) & Reference & 0.61 & \\
\hline & Alcohol use (Light drinker) & 0.73 & 0.32 & $0.392-1.369$ \\
\hline & Alcohol use (Heavy drinker) & 0.63 & 0.62 & $0.096-4.120$ \\
\hline & Physical activity (No) & Reference & 0.74 & \\
\hline & Physical activity (Mild) & 1.49 & 0.28 & $0.710-3.155$ \\
\hline & Physical activity (Moderate) & 1.31 & 0.51 & $0.577-2.989$ \\
\hline & Physical activity (Strenuous) & 1.16 & 0.79 & $0.386-3.486$ \\
\hline & Inflammation $(C R P \geq 10 \mathrm{mg} / \mathrm{L})$ & 0.25 & 0.18 & $0.032-1.936$ \\
\hline & AA:EPA & 0.98 & 0.30 & $0.951-1.015$ \\
\hline \multirow{20}{*}{ Depression $\left(R^{2}=0.1, p<0.001\right)$} & Age & 0.98 & 0.22 & $0.961-1.009$ \\
\hline & Gender (Male) & 0.88 & 0.66 & $0.490-1.581$ \\
\hline & Serum vitamin $\mathrm{B} 12(\mathrm{BL} \geq 450 \mathrm{pmol} / \mathrm{L}$ and $\mathrm{FL} \geq 450 \mathrm{pmol} / \mathrm{L})$ & Reference & & \\
\hline & Serum vitamin $\mathrm{B} 12(\mathrm{BL}<450$ and $\mathrm{FL} \geq 450 \mathrm{pmol} / \mathrm{L})$ & 0.77 & 0.41 & $0.428-1.418$ \\
\hline & Serum $25(\mathrm{OH}) \mathrm{D}(\mathrm{BL} \geq 100$ and $\mathrm{FL} \geq 100 \mathrm{nmol} / \mathrm{L})$ & Reference & 0.15 & \\
\hline & Serum $25(\mathrm{OH}) \mathrm{D}(\mathrm{BL}<75$ and $\overline{\mathrm{FL}} \geq 100)$ * & 1.96 & 0.05 & $1.002-4.106$ \\
\hline & Serum $25(\mathrm{OH}) \mathrm{D}(\mathrm{BL} 75-100$ and $\mathrm{FL}>100)$ & 1.57 & 0.16 & $0.836-2.955$ \\
\hline & BMI, $\mathrm{kg} / \mathrm{m}^{2}$ & 0.98 & 0.65 & $0.940-1.040$ \\
\hline & Tobacco use (Never) & Reference & 0.59 & \\
\hline & Tobacco use (Quit smoking) & 1.17 & 0.59 & $0.652-2.112$ \\
\hline & Tobacco use (current smoker) & 0.65 & 0.46 & $0.203-2.064$ \\
\hline & Alcohol use (Never) & Reference & 0.42 & \\
\hline & Alcohol use (Light drinker) & 1.49 & 0.20 & $0.808-2.755$ \\
\hline & Alcohol use (Heavy drinker) & 1.04 & 0.96 & $0.169-6.474$ \\
\hline & Physical activity (No) & Reference & 0.47 & \\
\hline & Physical activity (Mild) & 1.86 & 0.11 & $0.857-4.039$ \\
\hline & Physical activity (Moderate) & 1.63 & 0.26 & $0.695-3.823$ \\
\hline & Physical activity (Strenuous) & 1.80 & 0.34 & $0.535-6.060$ \\
\hline & Inflammation $(C R P>10 \mathrm{mg} / \mathrm{L})$ & 0.37 & 0.13 & $0.102-1.349$ \\
\hline & AA:EPA & 0.99 & 0.74 & $0.961-1.029$ \\
\hline
\end{tabular}


Table 9. Cont.

\begin{tabular}{|c|c|c|c|c|}
\hline TSL Parameter Improvement & Factor & $\operatorname{Exp}(B)$ & $p$ Value & $95 \% \mathrm{CI}$ \\
\hline \multirow{20}{*}{ Mental score $\left(R^{2}=0.1, p<0.001\right)$} & Age & 0.98 & 0.11 & $0.957-1.005$ \\
\hline & Gender (Male) & 0.83 & 0.55 & $0.472-1.493$ \\
\hline & Serum vitamin $\mathrm{B} 12(\mathrm{BL} \geq 450 \mathrm{pmol} / \mathrm{L}$ and $\mathrm{FL} \geq 450 \mathrm{pmol} / \mathrm{L})$ & Reference & & \\
\hline & Serum vitamin $\mathrm{B} 12(\mathrm{BL}<450$ and $\mathrm{FL} \geq 450 \mathrm{pmol} / \mathrm{L})$ & 0.84 & 0.58 & $0.474-1.516$ \\
\hline & Serum $25(\mathrm{OH}) \mathrm{D}(\mathrm{BL} \geq 100$ and $\mathrm{FL} \geq 100 \mathrm{nmol} / \mathrm{L})$ & Reference & 0.29 & \\
\hline & Serum $25(\mathrm{OH}) \mathrm{D}(\mathrm{BL}<75$ and $\overline{\mathrm{FL}} \geq 100)$ & 1.76 & 0.10 & $0.960-3.595$ \\
\hline & Serum $25(\mathrm{OH}) \mathrm{D}(\mathrm{BL} 75-100$ and $\mathrm{FL} \geq 100)$ & 1.18 & 0.59 & $0.639-2.192$ \\
\hline & BMI, $\mathrm{kg} / \mathrm{m}^{2}$ & 1.02 & 0.55 & $0.965-1.068$ \\
\hline & Tobacco use (Never) & Reference & 0.67 & \\
\hline & Tobacco use (Quit smoking) & 1.03 & 0.91 & $0.586-1.811$ \\
\hline & Tobacco use (current smoker) & 0.59 & 0.39 & $0.170-2.023$ \\
\hline & Alcohol use (Never) & Reference & 0.75 & \\
\hline & Alcohol use (Light drinker) & 1.11 & 0.73 & $0.602-2.053$ \\
\hline & Alcohol use (Heavy drinker) & 0.59 & 0.58 & $0.086-4.01$ \\
\hline & Physical activity (No) & Reference & 0.05 & \\
\hline & Physical activity (Mild) * & 2.46 & 0.02 & $1.155-5.23$ \\
\hline & Physical activity (Moderate) * & 2.26 & 0.05 & $1.002-5.27$ \\
\hline & Physical activity (Strenuous) * & 4.99 & 0.01 & $1.317-18.96$ \\
\hline & Inflammation $(C R P \geq 10 \mathrm{mg} / \mathrm{L})$ & 0.73 & 0.59 & $0.227-2.349$ \\
\hline & AA:EPA * & 0.98 & 0.03 & $0.956-0.998$ \\
\hline
\end{tabular}

* Significant predictors, BL = baseline, FL = Follow-up, BMI = Body Mass Index, Fruit, vegetable, and fish consumption were removed from model because of almost zero effect size and for simplicity. 


\section{Discussion}

This study found that participants in an intervention program aimed at chronic disease prevention that provides nutritional supplements showed significant improvement in self-reported depression and anxiety over the course of one year. This was a large database with over 16,000 participants who had completed the questionnaires, EQ-5D and the TSL, at program entry. At baseline, over half of these participants reported some level of depression and anxiety, suggesting that a large number of people suffer from subclinical mood disturbances. Severe and extreme depression and anxiety was reported in $5.2 \%$ of the population which is consistent with a prevalence of depression of $5.4 \%$ in Canadians [3,51].

Overall, significant improvements were found for depression and anxiety after one year in the program. This is notable given that the majority of the population reported only mild levels of depression and anxiety at baseline (effect size 0.21 and 0.22 , respectively). More notable, over $90 \%$ of those who reported severe or extreme depression or anxiety at program entry reported improvement at one year (effect size 1.85 and 1.94, respectively).

Vitamin D deficiency was highly prevalent among severely/extremely depressed/anxious participants and achieving physiological serum $25(\mathrm{OH}) \mathrm{D}$ concentrations (above $100 \mathrm{nmol} / \mathrm{L}$ ) was found to have a significant influence on mental health improvements in the context of the rest of the program, particularly for depression.

All participants received multiple nutritional supplements including the Vital 2 Platinum multivitamin/mineral supplement, vitamin B12, omega 3 and vitamin $\mathrm{D}_{3}$ supplementation. However, achieving serum 25(OH)D concentrations above $100 \mathrm{nmol} / \mathrm{L}$ and vitamin B12 levels above $450 \mathrm{pmol} / \mathrm{L}$, safely [37], positively influenced depression and anxiety outcomes. The results suggest that nutrient intervention impacts depression to a greater extent than anxiety, but both were positively influenced. Others have found that vitamin $\mathrm{D}_{3}$ supplementation has led to improvements in depression [40,52-57], yet others have not [58-60]. A meta-analysis demonstrated the importance of dose, frequency and achieving measurable increases in $25(\mathrm{OH}) \mathrm{D}$ concentrations in being able to detect favourable depression outcomes [61]. Our results support those of Kaplan et al. who demonstrated that vitamin B complex and multivitamin/mineral formulas have resulted in greater reductions in stress and anxiety compared with vitamin $\mathrm{D}_{3}$ supplementation alone [29]. A systematic review of the evidence demonstrates a significant number of trials that overall provide sufficient support for the use of $B$ vitamins in the treatment of stress and anxiety in the general population, the benefit of which may be augmented with a broad array of minerals [13]. It is hypothesized that assuring all of the necessary cofactors for all metabolic processes improves mental resilience to stress and thus improves one's ability to cope. Given that the clinical intervention involves vitamin $\mathrm{D}_{3}$ in combination with MVM and vitamin B12, among other nutrients, the authors posit that, where vitamin $\mathrm{D}_{3}$ was found to be a significant predictor of improvements, the magnitude was dependent upon an optimal background of other nutrients. While optimal vitamin D levels are necessary for nearly every cell, it is but one component needed for proper functioning of all metabolic systems of the body. Moreover, the absorption of certain nutrients such as vitamin B12 may be affected by different disease conditions (pernicious anemia, and H. pylori infection) or medications such as acid blockers or psychiatric medications that may inhibit vitamin $\mathrm{D}$ absorption. These may explain the discrepant results from other studies involving vitamin $\mathrm{D}_{3}$ or vitamin $\mathrm{B} 12$ as a stand-alone treatment.

More strenuous physical activity was found to be associated with improved mental health status. There is growing evidence that physical activity has protective effects not only on physical health but also on mental health, particularly depression and anxiety. Engaging in regular physical activity led to fewer depression and anxiety symptoms than did being inactive, which may also be related to vitamin D synthesis via sun exposure [62-64]. The anti-inflammatory effect of omega 3 have been successfully linked to preventing or treating depression $[65,66]$, and B vitamins appears to treat anxiety, depression and stress $[13,67]$, although we found the predominant effect for vitamin D. 
The strengths of the present study include the large community-based population. The authors are unaware of any other study of a clinical intervention with as many participants as included here. Further, the population was not limited to clinically depressed individuals and found beneficial effects for the population in general.

The main limitations of this study are the lack of details of the other treatment options participants engaged in outside of the program (e.g., mediation or counselling). The data analysed here were collected as part of a clinical intervention, a real life program not specifically designed for research; hence, we were not able to ensure compliance and a high drop-out rate was expected. We used intent-to-treat analysis and found results compatible with the results of per protocol analysis. Following program entry, participants were provided with a standard package of multiple nutrients (multivitamin/mineral, vitamin $\mathrm{D}_{3}$, omega-3 fatty acids, vitamin B12, vitamin $\mathrm{C}$ and probiotics). In addition, nearly half of the participants were recommended additional supplements based upon individual requirements - for example, magnesium may have been recommended to an individual experiencing leg cramps or constipation. Vitamin $\mathrm{D}_{3}$ supplementation in the program was targeted at achieving a serum 25(OH)D concentration above $100 \mathrm{nmol} / \mathrm{L}$ rather than a specific dose of vitamin $\mathrm{D}_{3}$, but the rest of the supplements were provided at the standard dose. Because the data are from a voluntary health and wellness program, albeit a clinical intervention, there is likely to be a selection bias. Further, due to the nature of the study we were not able to measure compliance to the program, but the results do reflect real-life response. Small but significant differences were detected in a baseline comparison between those who persisted in the program and those who did not; there was a significantly higher proportion (6.0\%) of severe/extreme depressed/anxious at baseline who dropped-out of the program in comparison with those who persisted to one year (2.7\%). In addition, the measurement of depression and anxiety was through a standardized questionnaire rather than a clinical assessment. The results presented here represent a real-life scenario rather than a clinical study.

Currently, the front line form of treatment for depression is psychopharmaceutical, but there is growing interest in exploring the role of nutrients. Nutritional status plays an important role in mental health, and poor nutrition may contribute to the pathogenesis of mental illness. Nutritional deficiencies could have an influence on brain structure and function, including mood, anxiety and depression. We found depression and anxiety were commonly reported in the participants of this clinical intervention. This analysis showed that improvements in depression and anxiety were associated with achieving serum 25(OH)D concentrations of at least $100 \mathrm{nmol} / \mathrm{L}$. A nutrient-based program aimed at achieving optimal nutrition may provide a safe, simple and economical means of supporting mental health.

\section{Conclusions}

Overall, this analysis of a large database sample $(n=16,020)$, in which over half of the population reported some level of depression and anxiety, confirms the high rate of people in the general population who suffer from mood and anxiety problems. The current study suggests that general mood may benefit from improved nutritional status. Nutritional status plays an important role in mental health, and poor nutrition may contribute to the pathogenesis of mental illness. Broad spectrum supplements with a focus on optimizing vitamin D status may provide a new paradigm for treatment and prevention of mental illness.

Supplementary Materials: The following are available online at http:/ /www.mdpi.com/2072-6643/10/2/152/s1, Table S1: Comparison of Multivitamin/mineral formulations: Vital 2 Platinum vs. EMPowerplus Table S2: Lifestyle characteristics of population at baseline according to the reported levels of anxiety/depression, Table S3: Comparison of change in reported level of depression and anxiety at one year between case and control groups.

Acknowledgments: The authors would like to thank Ken Fyie for his work in constructing the dataset and Brian Rankin for manuscript review.

Author Contributions: S.M.K., N.M. and J.R. designed the study; N.M. performed the statistical analysis; and N.M., S.M.K. and J.R. participated in the writing of the manuscript. All authors read and approved the final 
manuscript. The datasets used and/or analysed during the current study are available from the corresponding author on reasonable request.

Conflicts of Interest: The authors declare no conflict of interest. There was no funding provided directly for this work. Samantha Kimball and Naghmeh Mirhosseini are employed by the Pure North S'Energy Foundation, a not for profit organization. This affiliation does not alter authors' adherence to all Journal policies on sharing data and materials. J.R. does not receive any financial compensation from Pure North and is a full-time employee at the University of Canterbury.

\section{References}

1. Ferrari, A.J.; Charlson, F.J.; Norman, R.E.; Patten, S.B.; Freedman, G.; Murray, C.J.; Vos, T.; Whiteford, H.A. Burden of depressive disorders by country, sex, age, and year: Findings from the global burden of disease study 2010. PLoS Med. 2013, 10, 1-12. [CrossRef] [PubMed]

2. World Health Organization. The World Health Report 2001: Mental Health: New Understanding, New Hope; World Health Organization: Geneva, Switzerland, 2001; Available online: http:/ /www.who.int/whr/2001/en/ (accessed on 17 February 2016).

3. Mental Health Commission of Canada. Making the Case for Investing in Mental Health in Canada. 2013. Available online: https:/ /www.mentalhealthcommission.ca/sites/default/files/2016-06/Investing_in_ Mental_Health_FINAL_Version_ENG.pdf (accessed on 28 September 2015).

4. Sarris, J.; Logan, A.C.; Akbaraly, T.N.; Amminger, G.P.; Balanzá-Martínez, V.; Freeman, M.P.; Hibbeln, J.; Matsuoka, Y.; Mischoulon, D.; Mizoue, T.; et al. Nutritional medicine as mainstream in psychiatry. Lancet Psychiatry 2015, 2, 271-274. [CrossRef]

5. Moncrieff, J. Are antidepressants as effective as claimed? No, they are not effective at all. Can. J. Psychiatry 2007, 52, 96-97. [CrossRef] [PubMed]

6. Moncrieff, J. Misrepresenting harms in antidepressant trials. BMJ 2016, 352, i217. [CrossRef] [PubMed]

7. Middleton, H.; Moncrieff, J. They won't do any harm and might do some good: Time to think again on the use of antidepressants? Br. J. Gen. Pract. 2011, 61, 47-49. [CrossRef] [PubMed]

8. Martin, A.; Young, C.; Leckman, J.F.; Mukonoweshuro, C.; Rosenheck, R.; Leslie, D. Age effects on antidepressant-induced manic conversion. Arch. Pediatr. Adolesc. Med. 2004, 158, 773-780. [CrossRef] [PubMed]

9. Rucklidge, J.J.; Kaplan, B.J.; Mulder, R.T. What if nutrients could treat mental illness? Aust. N. Z. J. Psychiatry 2015, 49, 407-408. [CrossRef] [PubMed]

10. Lang, U.E.; Beglinger, C.; Schweinfurth, N.; Walter, M.; Borgwardt, S. Nutritional aspects of depression. Cell Physiol. Biochem. 2015, 37, 1029-1043. [CrossRef] [PubMed]

11. Kaplan, B.J.; Rucklidge, J.J.; McLeod, K.; Romijn, A. The emerging field of nutritional mental health: Inflammation, the microbiome, oxidative stress, and mitochondrial function. Clinic. Psychol. Sci. 2015, 3, 964-980. [CrossRef]

12. Kaplan, B.J.; Crawford, S.G.; Field, C.J.; Simpson, J.S.A. Vitamins, minerals, and mood. Psychol. Bull. 2007, 133, 747-760. [CrossRef] [PubMed]

13. Rucklidge, J.J.; Kaplan, B.J. Broad-spectrum micronutrient formulas for the treatment of psychiatric symptoms: A systematic review. Exp. Rev. Neurother. 2013, 13, 49-73. [CrossRef] [PubMed]

14. Sanchez-Villegas, A.; Delgado-Rodriguez, M.; Alonso, A.; Schlatter, J.; Lahortiga, F.; Serra Majem, L.; Martinez-Gonzalez, M.A. Association of the Mediterranean dietary pattern with the incidence of depression: The Seguimiento Universidad de Navarra/University of Navarra follow-up (SUN) cohort. Arch. Gen. Psychiatry 2009, 66, 1090-1098. [CrossRef] [PubMed]

15. Jacka, F.N.; Kremer, P.J.; Berk, M.; de Silva-Sanigorski, A.M.; Moodie, M.; Leslie, E.R.; Pasco, J.A.; Swinburn, B.A. A prospective study of diet quality and mental health in adolescents. PLOS ONE 2011, 6, e24805. [CrossRef] [PubMed]

16. Jacka, F.N.; Kremer, P.J.; Leslie, E.R.; Berk, M.; Patton, G.C.; Toumbourou, J.W.; Williams, J.W. Associations between diet quality and depressed mood in adolescents: Results from the Australian Healthy Neighbourhoods Study. Aust. N. Z. J. Psychiatry 2010, 44, 435-442. [CrossRef] [PubMed]

17. Jacka, F.N.; Pasco, J.A.; Mykletun, A.; Williams, L.J.; Hodge, A.M.; O’Reilly, S.L.; Nicholson, G.C.; Kotowicz, M.A.; Berk, M. Association of Western and traditional diets with depression and anxiety in women. Am. J. Psychiatry 2010, 167, 305-311. [CrossRef] [PubMed] 
18. Carroll, D.; Ring, C.; Suter, M.; Willemsen, G. The effects of an oral multivitamin combination with calcium, magnesium, and zinc on psychological well-being in healthy young male volunteers: A double-blind placebo-controlled trial. Psychopharmacology (Berlin) 2000, 150, 220-225. [CrossRef]

19. Harris, E.; Kirk, J.; Rowsell, R.; Vitetta, L.; Sali, A.; Scholey, A.B.; Pipingas, A. The effect of multivitamin supplementation on mood and stress in healthy older men. Hum. Psychopharmacol. 2011, 26, 560-567. [CrossRef] [PubMed]

20. Kennedy, D.O.; Veasey, R.; Watson, A.; Dodd, F.; Jones, E.; Maggini, S.; Haskell, C.F. Effects of high-dose $B$ vitamin complex with vitamin $C$ and minerals on subjective mood and performance in healthy males. Psychopharmacology (Berlin) 2010, 211, 55-68. [CrossRef] [PubMed]

21. Lewis, J.E.; Tiozzo, E.; Melillo, A.B.; Leonard, S.; Chen, L.; Mendez, A.; Woolger, J.M.; Konefal, J. The effect of methylated vitamin B complex on depressive and anxiety symptoms and quality of life in adults with depression. ISRN Psychiatry 2013, 2013, 621453. [CrossRef] [PubMed]

22. Rucklidge, J.J.; Andridge, R.; Gorman, B.; Blampied, N.; Gordon, H.; Boggis, A. Shaken but unstirred? Effects of micronutrients on stress and trauma after an earthquake: RCT evidence comparing formulas and doses. Hum. Psychopharmacol. 2012, 27, 440-454. [CrossRef] [PubMed]

23. Schlebusch, L.; Bosch, B.A.; Polglase, G.; Kleinschmidt, I.; Pillay, B.J.; Cassimjee, M.H. A double-blind, placebo-controlled, double-centre study of the effects of an oral multivitamin-mineral combination on stress. S. Afr. Med. J. 2000, 90, 1216-1223. [PubMed]

24. Sarris, J.; Logan, A.C.; Akbaraly, T.N.; Paul, A.G.; Balanza-Martinez, V.; Freeman, M.P.; Hibbeln, J.; Matsuoka, Y.; Mischoulon, D.; Mizoue, T.; et al. International Society for Nutritional Psychiatry Research consensus position statement: Nutritional medicine in modern psychiatry. World Psychiatry 2015, 14, 370-371. [CrossRef] [PubMed]

25. Kaplan, B.J.; Simpson, J.S.; Ferre, R.C.; Gorman, C.P.; McMullen, D.M.; Crawford, S.G. Effective mood stabilization with a chelated mineral supplement: An open-label trial in bipolar disorder. J. Clin. Psychiatry 2001, 62, 936-944. [CrossRef] [PubMed]

26. Popper, C.W. Do vitamins or minerals (apart from lithium) have mood-stabilizing effects? J. Clin. Psychiatry 2001, 62, 933-935. [CrossRef] [PubMed]

27. Simmons, M. Nutritional approach to bipolar disorder. J. Clin. Psychiatry 2003, 64, 338-339. [CrossRef] [PubMed]

28. Frazier, E.A.; Fristad, M.A.; Arnold, L.E. Feasibility of a nutritional supplement as treatment for pediatric bipolar spectrum disorders. J. Altern. Complement. Med. 2012, 18, 678-685. [CrossRef] [PubMed]

29. Kaplan, B.J.; Rucklidge, J.J.; Romijn, A.R.; Dolph, M. A randomised trial of nutrient supplements to minimise psychological stress after a natural disaster. Psychiatry Res. 2015, 228, 373-379. [CrossRef] [PubMed]

30. Rucklidge, J.; Johnstone, J.; Harrison, R.; Boggis, A. Micronutrients reduce stress and anxiety in adults with Attention-Deficit/Hyperactivity Disorder following a 7.1 earthquake. Psychiatry Res. 2011, 189, 281-287. [CrossRef] [PubMed]

31. Rucklidge, J.J.; Blampied, N.; Gorman, B.; Gordon, H.A.; Sole, E. Psychological functioning 1 year after a brief intervention using micronutrients to treat stress and anxiety related to the 2011 Christchurch earthquakes: A naturalistic follow-up. Hum. Psychopharmacol. 2014, 29, 230-243. [CrossRef] [PubMed]

32. Gosney, M.A.; Hammond, M.F.; Shenkin, A.; Allsup, S. Effect of micronutrient supplementation on mood in nursing home residents. Gerontology 2008, 54, 292-299. [CrossRef] [PubMed]

33. Gariballa, S.; Forster, S. Effects of dietary supplements on depressive symptoms in older patients: A randomised double-blind placebo-controlled trial. Clin. Nutr. 2007, 26, 545-551. [CrossRef] [PubMed]

34. Heaney, R.P. Toward a physiological referent for the vitamin D requirement. J. Endocrinol. Investig. 2014, 37, 1127-1130. [CrossRef] [PubMed]

35. Mason, J.B. Vitamins, Trace Minerals, and Other Micronutrients; Elsevier Saunders: Philadelphia, PA, USA, 2011.

36. Lamers, L.M.; Bouwmans, C.A.; van Straten, A.; Donker, M.C.; Hakkaart, L. Comparison of EQ-5D and SF-6D utilities in mental health patients. Health Econ. 2006, 15, 1229-1236. [CrossRef] [PubMed]

37. Kimball, S.M.; Mirhosseini, N.; Holick, M.F. Evaluation of vitamin D3 intakes up to 15,000 international units/day and serum 25-hydroxyvitamin D concentrations up to $300 \mathrm{nmol} / \mathrm{L}$ on calcium metabolism in a community setting. Dermatoendocrinol 2017, 13, e1300213. [CrossRef] [PubMed]

38. Anglin, R.E.; Samaan, Z.; Walter, S.D.; McDonald, S.D. Vitamin D deficiency and depression in adults: Systematic review and meta-analysis. Br. J. Psychiatry 2013, 202, 100-107. [CrossRef] [PubMed] 
39. Polak, M.A.; Houghton, L.A.; Reeder, A.I.; Harper, M.J.; Conner, T.S. Serum 25-hydroxyvitamin D concentrations and depressive symptoms among young adult men and women. Nutrients 2014, 6, 4720-4730. [CrossRef] [PubMed]

40. Jorde, R.; Sneve, M.; Figenschau, Y.; Svartberq, J.; Waterloo, K. Effects of vitamin D supplementation on symptoms of depression in overweight and obese subjects: Randomized double blind trial. J. Intern. Med. 2008, 264, 599-609. [CrossRef] [PubMed]

41. DeLuca, G.C.; Kimball, S.M.; Kolasinski, J.; Ramagopalan, S.V.; Ebers, G.C. Review: The role of vitamin D in nervous system health and disease. Neuropathol. Appl. Neurobiol. 2013, 39, 458-484. [CrossRef] [PubMed]

42. Janz, T.; Pearson, C. Vitamin D Blood Levels of Canadians; Statistics Canada 82-624-X; Statistics Canada: Ottawa, ON, Canada, 2011.

43. Pearson, C.; Janz, T.; Ali, J. Mental and Substance Use Disorders in Canada; Statistics Canada 82-624-X; Statistics Canada: Ottawa, ON, Canada, 2013.

44. Huskisson, E.; Maqqini, S.; Ruf, M. The role of vitamins and minerals in energy metabolism and well-being. J. Int. Med. Res. 2007, 35, 277-289. [CrossRef] [PubMed]

45. Allen, L.H. How common is vitamin B-12 deficiency? Am. J. Clin. Nutr. 2009, 89, 6935-6965. [CrossRef] [PubMed]

46. Sobocki, P.; Ekman, M.; Agren, H.; Krakau, I.; Runeson, B.; Martensson, B.; Jonsson, B. Health-related quality of life measured with EQ-5D in patients treated for depression in primary care. Value Health 2007, 10, 153-160. [CrossRef] [PubMed]

47. Statistic Canada. Table 105-0507-Measured Adult Body Mass Index (BMI), by Age Group and Sex, Household Population Aged 18 and over Excluding Pregnant Females, Canada (Excluding Territories), Occasional (Number Unless Otherwise Noted). CANSIM. 2018. Available online: http:/ /www5.statcan.gc. $\mathrm{ca} /$ cansim/a26?lang=eng\&id=1050507 (accessed on 24 June 2017).

48. Johnson, J.A.; Pickard, A.S. Comparison of the EQ-5D and SF-12 health surveys in a general population survey in Alberta, Canada. Med. Care 2000, 38, 115-121. [CrossRef] [PubMed]

49. Johnson, J.A.; Coons, S.J. Comparison of the EQ-5D and SF-12 in an adult US sample. Qual. Life Res. 1998, 7, 155-166. [CrossRef] [PubMed]

50. De Smedt, D.; Clays, E.; Annemans, L.; De Bacquer, D. EQ-5D versus SF-12 in coronary patients: Are they interchangeable? Value Health 2014, 17, 84-89. [CrossRef] [PubMed]

51. Canada Health. A Report on Mental Illnesses in Canada; Canada HCEBMII, Ed.; Health Canada: Ottawa, ON, Canada, 2002; p. 108.

52. Tosunbayraktar, G.; Bas, M.; Kut, A.; Buyukkaragoz, A.H. Low serum 25(OH)D levels are associated to higher BMI and metabolic syndrome parameters in adult subjects in Turkey. Afr. Health Sci. 2015, 15, 1161-1169. [CrossRef] [PubMed]

53. Ekwaru, J.P.; Zwicker, J.D.; Holick, M.F.; Giovannucci, E.; Veugelers, P.J. The Importance of Body Weight for the Dose Response Relationship of Oral Vitamin D Supplementation and Serum 25-Hydroxyvitamin D in Healthy Volunteers. PLoS ONE 2014, 9, e111265. [CrossRef] [PubMed]

54. Robien, K.; Oppeneer, S.J.; Kelly, J.A.; Hamilton-Reeves, J.M. Drug-vitamin D interactions: A systematic review of the literature. Nutr. Clin. Pract. 2013, 28, 194-208. [CrossRef] [PubMed]

55. Jamilian, H.; Bagherzadeh, K.; Nazeri, Z.; Hassanijirdehi, M. Vitamin D, parathyroid hormone, serum calcium and phosphorus in patients with schizophrenia and major depression. Int. J. Psychiatry Clin. Pract. 2013, 17, 30-34. [CrossRef] [PubMed]

56. Mozaffari-Khosravi, H.; Nabizade, L.; Yassini-Ardakani, S.M.; Hadinedoushan, H.; Barzegar, K. The effect of 2 different single injections of high dose of vitamin D on improving the depression in depressed patients with vitamin D deficiency: A randomized clinical trial. J. Clin. Psychopharmacol. 2013, 33, 378-385. [CrossRef] [PubMed]

57. Shaffer, J.A.; Edmondson, D.; Wasson, L.T.; Falzon, L.; Homma, K.; Ezeokoli, N.; Li, P.; Davidson, K.W. Vitamin D supplementation for depressive symptoms: A systematic review and meta-analysis of randomized controlled trials. Psychosom. Med. 2014, 76, 190-196. [CrossRef] [PubMed]

58. Dumville, J.C.; Miles, J.N.; Porthouse, J.; Cockayne, S.; Saxon, L.; King, C. Can vitamin D supplementation prevent winter-time blues? A randomised trial among older women. J. Nutr. Health Aging 2006, 10, 151-153. [PubMed] 
59. Dean, A.J.; Bellgrove, M.A.; Hall, T.; Phan, W.M.; Eyles, D.W.; Kvaskoff, D.; McGrath, J.J. Effects of vitamin D supplementation on cognitive and emotional functioning in young adults-A randomised controlled trial. PLOS ONE 2011, 6, e25966. [CrossRef] [PubMed]

60. Sanders, K.M.; Stuart, A.L.; Williamson, E.J.; Jacka, F.N.; Dodd, S.; Nicholson, G.; Berk, M. Annual high-dose vitamin D3 and mental well-being: Randomised controlled trial. Br. J. Psychiatry 2011, 198, 357-364. [CrossRef] [PubMed]

61. Spedding, S. Vitamin D and depression: A systematic review and meta-analysis comparing studies with and without biological flaws. Nutrients 2014, 6, 1501-1518. [CrossRef] [PubMed]

62. Griffiths, A.; Kouvonen, A.; Pentti, J.; Oksanen, T.; Virtanen, M.; Salo, P.; Väänänen, A.; Kivimäki, M.; Vahtera, J. Association of physical activity with future mental health in older, mid-life and younger women. Eur. J. Public Health 2014, 24, 813-818. [CrossRef] [PubMed]

63. Strohle, A. Physical activity, exercise, depression and anxiety disorders. J. Neural Transm. 2009, 116, 777-784. [CrossRef] [PubMed]

64. Stanton, R.; Reaburn, P. Exercise and the treatment of depression: A review of the exercise program variables. J. Sci. Med. Sport 2014, 17, 177-182. [CrossRef] [PubMed]

65. Grosso, G.; Galvano, F.; Marventano, S.; Malaguarnera, M.; Bucolo, C.; Drago, F.; Filippo, C.F. Omega-3 Fatty Acids and Depression: Scientific Evidence and Biological Mechanisms. Oxid. Med. Cell. Longev. 2014, 2014, 313570. [CrossRef] [PubMed]

66. Miller, A.H.; Raison, C.L. The role of inflammation in depression: From evolutionary imperative to modern treatment target. Nat. Rev. Immunol. 2016, 16, 22-34. [CrossRef] [PubMed]

67. Coppen, A.; Bolander-Gouaille, C. Treatment of depression: Time to consider folic acid and vitamin B12. J. Psychopharmacol. 2005, 19, 59-65. [CrossRef] [PubMed]

(C) 2018 by the authors. Licensee MDPI, Basel, Switzerland. This article is an open access article distributed under the terms and conditions of the Creative Commons Attribution (CC BY) license (http://creativecommons.org/licenses/by/4.0/). 